\title{
The sponsors and ALERT: expectations and obligations
}

\author{
H KOBER \\ German Leprosy Relief Association, P.O. Box 348, \\ 8700 Würzburg 11, Germany
}

On behalf of the International Federation of Anti-Leprosy Associations (ILEP) I should like to express my heartfelt congratulations and my thanks to all those who contributed to the foundation of ALERT, to all those who during the last 20 years have made ALERT one of the most important international training centres for leprosy, and to all those who are responsible for this project today.

At this moment, I think with particular respect and thanks of the first Executive Director of ALERT who was a good friend of mine and of many others, Onni Niskanen. He loved this country and its people, he helped to establish ALERT and put it on the right road. We will never forget onni Niskanen and his involvement in ALERT.

I am pleased that the Government of Ethiopia has realized the value of an institution like ALERT and has supported ALERT during all these years, even in difficult times, and that it is represented today by high officials.

First, I should like to say some words about ILEP, as the representative of which I am talking to you here.

I may speak to you as the representative of ILEP and at the same time as the representative of the German Leprosy Relief Association which, by the decision of ILEP members, acts as coordinator of all their assistance and support to Ethiopia and also ALERT.

The reason for this is that the German Leprosy Relief Association is a real child of Ethiopia. The first leprosy colony, which was supported by the German Leprosy relief Association, was at San Antoine near Harrar, and the first leprosy project that was built up with the help of the German Leprosy Relief Association in the year 1958 was the leprosy relief centre, Bisidimo. 
Since 1957/58, the German Leprosy Relief Association has invested 47 million DM in the fight against leprosy in Ethiopia including ALERT.

Now, let us have a look at ILEP.

ILEP, the International Federation of Anti-Leprosy Associations (1966), brings together 23 national bodies based in 21 industrialized countries concerned with helping leprosy sufferers. They cooperate with 99 countries where leprosy is endemic: 46 countries in Africa, 22 countries in Asia, 15 countries in the Americas, 5 in Europe, and 11 in Oceania.

Altogether these countries constitute a kind of international leprosy community, where more than 2.5 million individual donors, through the 23 member organisations of ILEP, are cooperating with over one million leprosy patients through government and private projects.

Ethiopia is one of the oldest members of this international community, and according to the well-organised national leprosy control programme and ALERT, one of the most important ones.

As a matter of fact, in 1984, more than 900 projects with $1,250,000$ leprosy patients were supported by a total budget of nearly US $\$ 34$ million, of which $39 \%$ was expended in Asia, $38 \%$ in Africa, over 88 on research programmes, and the remainder in the Americas, Europe and Oceania.

ILEP is a coordinating body whose member organizations are partners in a working community. Everything, except information, is decentralized within the Federation: funds and resources, operation activities in the field, decision-making.

Through the coordinating structures of the Federation however, all partners of the community work together. The Federation itself is represented in the field mainly through its coordinating members, called coordinators as mentioned above.

The various aspects of leprosy work, social and humanitarian as well as medical and scientific, are to be found among ILEP's activities, including leprosy control, research, training, health education, and rehabilitation.

In order to cover all these aspects of work, ILEP set up a series of commissions, ad hoc working groups, and temporary partnerships. The most important commission is without doubt, the Medical Commission, which assembles the most experienced leprologists in the world. Other working groups deal with 
health education, leprosy and primary health care, leprosy and tuberculosis, teaching and learing materials, and last but not least there is an ad hoc working group for training which is of the utmost importance, above all for ALERT.

Since the very moment we realised that monotherapy i.e. the application of DDS alone in leprosy treatment, produces resistance and thus prevents the curing of the disease, it became evident that it would be necessary to use combined drug regimens which would mean the treatment of the disease with a combination of different drugs. Taking this into consideration, even more importance has now to be attached to the training of medical personnel, which has always played a key role in leprosy control and the fight against leprosy.

And with this, the importance and responsibility of ALERT at present and in the future becomes clear.

ILEP members are very well aware of ALERT's importance and have therefore continuously supported the centre.

In all, the ILEP members have contributed a total of $20,866,400$ Birr to ALERT.

Based on the annual budget of ALERT, which is presented to the ILEP members by the Executive Director of ALERT and by the Coordinator at the December session of ILEP, the financing of the budget follows a specific system which considers the financial power of the individual member association and fixes the percentage of the contribution analogous to the ILEP quota system.

For the years 1969 to 1985, ILEP support was as shown in Table 1 .

In 1986 ILEP member associations are prepared to make available a total amount of $2,538,883$ Birr which includes the cash budget and the so-called sponsored staff.

The allocations are as shown in Table 2 .

of course, with this amount, not all the needs of ALERT can be met but there is no doubt that ILEP members make a considerable contribution to the running of ALERT.

This means that ILEP has certain expectations as regards ALERT, its board and its management.

ALERT has to make sure that the best training for doctors and medical staff is guaranteed, a training that always needs to be oriented towards the latest findings in leprosy. 
Table 1. ILEP - Contributions towards ALERT 1969 - 1985

\begin{tabular}{|c|c|c|c|c|}
\hline \multirow[t]{2}{*}{ ILEPP Members } & \multirow[t]{2}{*}{$\begin{array}{l}\text { Period of } \\
\text { contribution }\end{array}$} & \multirow[t]{2}{*}{$\begin{array}{l}\text { No. of } \\
\text { years }\end{array}$} & \multicolumn{2}{|c|}{$\begin{array}{l}\text { Total } \\
\text { contributions }\end{array}$} \\
\hline & & & Birr & 8 \\
\hline DAHW & $1969-1985$ & 17 & $5,390,958$ & 25.85 \\
\hline AI & $1972-1985$ & 14 & $1,210,764$ & 5.80 \\
\hline ALES & $1969-1985$ & 17 & $1,336,322$ & 6.40 \\
\hline AIM & $1975-1985$ & 11 & 998,316 & 4.78 \\
\hline DFB & $1971-1985$ & 15 & $1,694,682$ & 8.12 \\
\hline FFF & $1972-1985$ & 9 & 726,516 & 3.48 \\
\hline FFL & $1972-1985$ & 14 & 387,880 & 1.86 \\
\hline FP & $1980-1985$ & 6 & 617,966 & 2.96 \\
\hline LEPRA UK & $1982-1985$ & 4 & 588,920 & 2.82 \\
\hline LTB, NEW ZEALAND & 1985 & 1 & 14,356 & 0.07 \\
\hline NSL & $1969-1985$ & 17 & $2,765,930$ & 13.26 \\
\hline $\mathrm{OM}$ & $1982-1984$ & 3 & 90,000 & 0.43 \\
\hline $\mathrm{RD}$ & $1976-1985$ & 10 & 212,898 & 1.02 \\
\hline $\mathrm{RN}$ & $1974-1985$ & 12 & $1,254,256$ & 6.01 \\
\hline RS & $1970-1985$ & 14 & $2,386,454$ & 11.44 \\
\hline SLC & $1971-1985$ & 7 & 657,084 & 3.15 \\
\hline TIMI & $1970-1985$ & 16 & 533,066 & 2.55 \\
\hline
\end{tabular}

Total amount in Ethiopian Birr

$\underline{20,866,368} \underline{1008}$

corresponding to US\$ $43,193,385$

I should also like to address the Government of this country: The international character of this centre should be maintained. ALERT is one of the best training centres for leprosy, if not the best, in Africa and the whole world.

Further, I have a message for all African countries in the Organisation of African Unity: This centre is called "All Africa". The founders and all those who maintain this centre today, first of all had in mind that this centre should be a training centre for the African continent. We all know that 
Table II ILEP Participation in ALERT 1986 Budget

\begin{tabular}{|c|c|c|c|}
\hline Name of ILEP member & $\begin{array}{l}\text { Sponsored } \\
\text { staff } \\
\text { Birr }\end{array}$ & $\begin{array}{c}\text { Cäsh } \\
\text { contribution } \\
\text { Birr }\end{array}$ & $\begin{array}{c}\text { Total } \\
\text { confirmed } \\
\text { Birr }\end{array}$ \\
\hline Amici dei Lebbrosi & & 196,900 & 196,900 \\
\hline Emaus Switzerland & & 147,675 & 147,675 \\
\hline American Leprosy Missions & 96,400 & 51,275 & 147,675 \\
\hline Damien Foundation Belgium & & 113,723 & 113,723 \\
\hline German Leprosy Relief Ass. & 148,400 & 294,540 & 442,940 \\
\hline Fond. Follereau France & & 253,845 & 253,845 \\
\hline Fond. Follereau Luxenbourg & & 49,225 & 49,225 \\
\hline Fame Pereo Canada & & 147,675 & 147,675 \\
\hline LEPRA UK & & 147,675 & 147,675 \\
\hline $\begin{array}{l}\text { Leprosy Trust Board, } \\
\text { New Zealand }\end{array}$ & 5,000 & 5,000 & \\
\hline Netherlands Leprosy & & & \\
\hline Relief Ass. & 137,000 & 59,900 & 196,900 \\
\hline Save the Children Dermark & & 51,250 & 51,250 \\
\hline Save the Children Norway & 149,900 & & 149,900 \\
\hline Save the Children Sweden & 208,900 & 22,700 & 231,600 \\
\hline Le Secours aux Lepr. Canada & & 196,900 & 196,900 \\
\hline The Leprosy Mission UK & 30,000 & 30,000 & 60,000 \\
\hline
\end{tabular}

Corresponding to US\$5,255,480

many of the countries of this continent have big problems. Nevertheless they should show sympathy and recognition and provide some support to ALERT. I am very pleased that in this respect steps have been taken again in ALERT's jubilee year and I should like to encourage the management to follow this up.

And, finally, an address to the international organisations that do not belong to ILEP: Please continue to give your generous support, as in the past. It must be our common aim 
to integrate the treatment of leprosy patients into the general health services and thus make leprosy be considered a disease like any other disease. This aim can only be achieved if we train medical staff adequately. To teach teachers is the task of ALERT.

Let us therefore cooperate in solidarity and friendship for the benefit of this excellent project and for the benefit of the people who need our help. 